\section{Why are more otorhinolaryngology surgeons dying from Covid-19 than any other surgical specialty?}

\author{
Daryll Baker* \\ Department of Surgery, Royal Free Hospital, London NW3 2QG, UK
}

Covid-19 infection is caused by the coronavirus SARS$\mathrm{CoV}-2$. This has resulted in the present pandemic from which thousands of people have died including many front-line health care workers. Of the surgeons who have died from covid-19 it would appear that otorhinolaryngology surgeons have made the largest sacrifice (Figure 1) [1].

The potential explanations for this are discussed.

\section{The type of surgery and the mode of transmission}

Although Covid-19 is a new disease and the exact methods of spread are still being determined (US Centers for Disease Control and Prevention), in general, respiratory virus infection occurs through contact (direct or indirect), droplet spray in short range transmission and aerosol in long-range transmission (airborne transmission) [2]. That is, the source of the virus is primarily the patient's nose and mouth and the surgeons recipient entry point is the mouth, nose and eyes.

Otorhinolaryngology surgery involves working on the patients two potential coronavirus source areas and placing the surgeons own potential portals of entry in close proximity to these sources during the procedure. In patients where Covid-19 is not suspected and appropriate personal protective equipment (PPE) not worn the risk of surgeon infection must be increased.

\section{Covid Related Surgeon deaths by specialty}

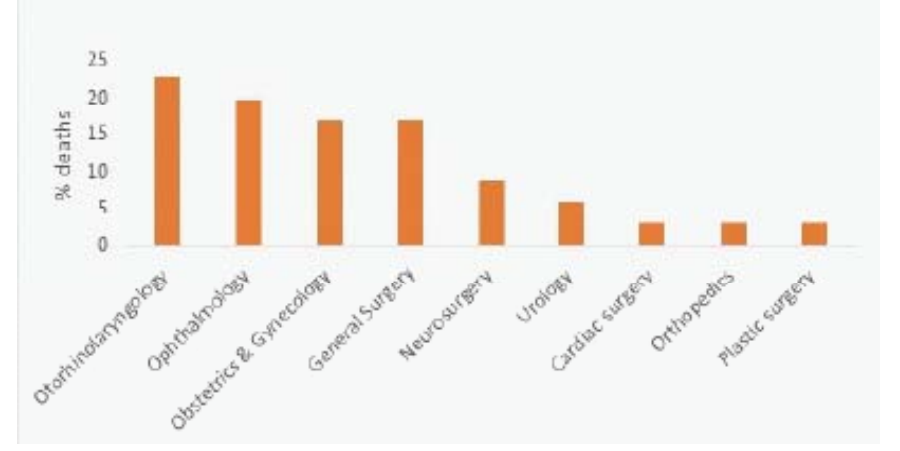

\section{More Information}

*Address for Correspondence: Daryll Baker, PhD., FRCS, Consultant Surgeon, Department of Surgery, Royal Free Hospital, London NW3 2QG, UK, Email daryll.baker@nhs.net

Submitted: 05 February 2020

Approved: 20 June 2020

Published: 22 June 2020

How to cite this article: Baker D. Why are more otorhinolaryngology surgeons dying from Covid-19 than any other surgical specialty? Heighpubs Otolaryngol Rhinol. 2020; 4: 006-007.

DOI: 10.29328/journal.hor.1001018

Copyright: (c) 2020 Baker D. This is an open access article distributed under the Creative Commons Attribution License, which permits unrestricted use, distribution, and reproduction in any medium, provided the original work is properly cited.

(W) Check for updates

(1) OPEN ACCESS

\section{The increased workload in infected patients}

During the present pandemic the number of tracheostomy interventions being undertaken has significantly increase. (In our unit from an average of 3 per month to 30 per month). Presently these are undertaken on Covid-19 infected patients who are unwell on the intensive care unit. The main indications are unstable airways, significant laryngeal and tongue oedema and to assist slow weaning.

We have also noticed an increased number of tracheostomy tube exchanges. These are usually for "cuff leaks" and it is felt due to the degree of tracheal oedema reducing as the patient improves. Initially the failure to use adjustable flange tracheostomy tubes was also a reason for replacement.

Although the tracheostomy insertions are normally undertaken via a percutaneous route, due to manpower resources the otorhinolaryngology surgeons are performing more open procedures (in our unit all but one have to date been via open surgery).

This increased work load undertaking a procedure, which despite the best surgical techniques will involve some aerosolization of respiratory droplets, will result in increased individual surgeon exposure to infection. In our unit PPE has always been amply available, but the increase exposure and the increased doffing of PPE will by its nature increase the likelihood of surgeon exposure. 
The increase workload will result in the recruitment of surgeons undertaking the open procedures that, although fully trained, may not have a large procedure experience or recent currency. This on, top of working with nurses and anaesthetist similarly disposed, along with the reduced manual dexterity of full operative PPE increases the risk of exposure.

In conclusion, there is a suggestion that more otorhinolaryngology surgeons are dying from Covid-19 than other surgical specialties. This is likely to be the result of increased viral exposure due to the nature of the operation and the increased demand for the operation.
This is best managed by acknowledging the risk and ensuring there are adequate numbers of surgeons who are current in performing the procedure available to minimise exposure as much as possible.

\section{References}

1. Ing EB, Xu EB, Salimi A, Torun N. Physician Deaths from Corona Virus Disease (COVID-19). medRxiv preprint. 2020.

2. Moriyama M, Hugentobler WJ, Iwasaki A. Seasonality of Respiratory infections. Annu Rev Virol. 2020. 7: 1-2.

Pubmed: https://pubmed.ncbi.nlm.nih.gov/32196426 